\title{
USULAN PERBAIKAN RUTE PENDISTRIBUSIAN PRODUK DENGAN MENGGUNAKAN ANALISIS BULLWHIP EFFECT, METODE NEAREST INSERT DAN NEAREST NEIGHBOR (STUDI KASUS DI PT. YNP)
}

\author{
Iphov Kumala Sriwana ${ }^{1}$ Ahmad $^{2}$ dan Audi Frisbert Rewa ${ }^{2}$ \\ Program Studi Teknik Industri, Universitas Tarumanagara \\ Program Studi Teknik Industri, Universitas Tarumanagara \\ e-mail: audi.rewa@gmail.com
}

\begin{abstract}
ABSTRAK
PT.YNP sebagai salah satu perusahaan yang bergerak dibidang manufaktur, dan mempunyai beberapa masalah yang terjadi di dalam perusahaan. Salah satunya terdapat pada bagian distribusi dan produksi. Setelah melakukan penelitian maka didapatkan hasil berupa tingkat bullwhip effect yang terjadi pada beberapa kota, yaitu pada kota Banjarmasin sebesar 1.0 untuk produk HK910A dan HK910B, Semarang sebesar 1.0 untuk produk BL75C dan HK910A, Surakarta sebesar 1.0 untuk produk HK910A dan HK910B, Makassar sebesar 0.9 untuk produk BL75c, HK910A dan HK910B, Bekasi sebesar 1.1 untuk produk BL75C, Bandung sebesar 1.0 untuk produk BL75C, HK910A, HK910B, Medan sebesar 1.2 untuk produk BL75C. berdasarkan penelitian didapatkan juga Rute pendistribusian yang lebih optimal dibandingkan dengan rute pendistribusian awal, yaitu Rute 1 Jakarta-Banjarmasin-Makassar-Jakarta, Rute 2 adalah Jakarta-Semarang-Surakarta-Jakarta, dan Rute 3 adalah Jakarta-Bekasi-BandungMedan-Jakarta.
\end{abstract}

Kata kunci: Bullwhip Effect, Matrik Penghematan, Nearest Insert, Nearest Neighbor.

\begin{abstract}
PT.YNP as one of the companies engaged in manufacturing, and has some problems that occur in the company. One was found on the distribution and production. After doing research, it is obtained in the form of level bullwhip effect which occurs in some cities, namely in Banjarmasin city of 1.0 for products HK910A and HK910B, Semarang equal to 1.0 for products BL75C and HK910A, Surakarta equal to 1.0 for products HK910A and HK910B, Makassar 0.9 to BL75c products, HK910A and HK910B, Bekasi by 1.1 for product BL75C, Bandung equal to 1.0 for products BL75C, HK910A, HK910B, Medan by 1.2 for product BL75C. Based on research obtained also these distributions is more optimal than route the distribution of the initial, i.e. Route 1 Jakarta - Banjarmasin-Makassar-Jakarta, Route 2 is a JakartaSemarang-Surakarta-Jakarta, and Route 3 is Jakarta-Bekasi-Bandung-Medan-Jakarta
\end{abstract}

Key word: Bullwhip Effect, Saving Matrix, Nearest insert, Nearest Neighbor.

\section{PENDAHULUAN}

Ketatnya persaingan bisnis pada saat ini, membuat perusahaan berlomba-lomba untuk meningkatkan kualitas atau kinerja dari sistem yang telah ada. Hal ini tentunya berkaitan juga dengan semakin dekatnya pembukaan MEA (Masyarakat Ekonomi ASEAN) yang berlangsung pada tahun 2016, karena dengan adanya MEA tentunya akan banyak perusahaan asing yang masuk ke Indonesia dan akan merebut pangsa pasar yang ada di Indonesia, keadaan ini membuat para pelaku bisnis ketakutan akan semakin berkurangnya keuntungan yang nantinya akan didapatkan oleh perusahaan mereka. Peningkatan tersebut dapat dilakukan dengan berbagai macam cara. Seperti melakukan peningkatan pada sistem agar sistem tersebut dapat berjalan lebih efektif dan effisien. Peningkatan yang dilakukan berhubungan dengan pengaturan aliran material barang, uang, dan juga informasi. Salah satu cara dengan melakukan peningkatan pada bagian pengiriman perusahaan. PT. YNP sebagai salah satu perusahaan yang bergerak di bidang manufaktur, dan mempunyai beberapa masalah yang terjadi di dalam perusahaan. Salah satunya terdapat pada bagian distribusi dan produksi. Tujuan penelitian mengidentifikasikan faktor yang menyebabkan terjadinya Bullwhip effect, mengukur tingkat bullwhip effect, dan mencari solusi yang digunakan untuk mengurangi atau mencegah terjadinya bullwhip effect pada perusahaan, serta mencari jalur pendistribusian yang lebih optimal. 
Usulan Perbaikan Rute Pendistribusian produk dengan Menggunakan Analisis Bullwhip Effect, Metode Nearest Insert dan Nearest Neighbor (Studi Kasus di PT. YNP)

Iphov Kumala Sriwana, Ahmad dan Audi Frisbert Rewa

Supply chain adalah suatu jaringan perusahaan-perusahaan yang secara bersamasama bekerja untuk menciptakan dan menghantarkan suatu produk ke tangan pemakai akhir [1]. Chopra \& Meindl mengatakan Supply chain adalah suatu kelompok yang terlibat secara langsung atau tidak langsung dalam memenuhi kebutuhan dari konsumen [2]. Herjanto mengatakan bahwa supply chain merupakan sekumpulan aktivitas dan keputusan yang saling terkait untuk mengintegrasikan pemasok, manufaktur, gudang, jasa transportasi, pengecer dan konsumen secara efisien [3].

Supply Chain Management merupakan sesuatu yang sangat kompleks sekali, dimana banyak hambatan yang dihadapi dalam implementasinya, sehingga dalam implementasinya membutuhkan tahapan mulai dari tahapan perancangan sampai tahapan evaluasi dan continuous improvement [4]. Manajemen logistik didefinisikan sebagai proses pengelolaan yang strategis terhadap pemindahaan dan penyimpanan barang, suku cadang dan barang jadi dari supplier, di antara fasilitas-fasilitas perusahaan dan kepada para pelanggan [5]. Logistik adalah proses yang terorganisasi dimana mengatur aliran barang dagangan dari sumber pasok ke vendor, penggrosir atau distributor melalui fungsi proses internal, sampai barang dagangan terjual dan sampai ke tangan pelanggan [6].

Bullwhip effect adalah suatu fenomena dimana permintaan kepada supplier memiliki variasi yang besar daripada penjualan yang dilakukan kepada buyer dan terjadi distorsi kepada level supply chain yang lebih tinggi [7].

Menurut Davids Simchi-levi, dkk, dalam buku Designing and managing the supply chain, adalah sebagai berikut "Peningkatan variability dari level bawah menuju level atas dan dalam suatu network supply chain". Perhitungan bullwhip effect dapat dihitung dengan menggunakan rumus sebagai berikut:

$$
B E=\frac{C V \text { order }}{C V \text { jual }}
$$

\section{Di mana:}

$$
C V \text { order }=\frac{\sigma \text { order }}{\mu \text { order }}
$$

$$
\begin{aligned}
& C V \text { jual }=\frac{\sigma j u a l}{\mu j u a l} \\
& \sigma=\sqrt{\frac{\sum_{i=1}^{n}(X i-\mu)}{n-1}} \\
& \mu=\frac{\sum_{i=1}^{n} X i}{n}
\end{aligned}
$$

Adapun penyebab terjadinya Bullwhip effect antara lain adalah demand forecasting, batch ordering, fluktuasi harga dan perubahan pemesanan.

Transportasi adalah suatu kegiatan memindahkan produk ke kelas yang berbeda didalam supply chain [2]. Menurut Punjawan, transportasi adalah suatu kegiatan yang memungkinkan kita untuk memindahkan suatu produk dari lokasi dimana dia di produksi ke lokasi konsumen/pemakai yang sering kali dibatasi oleh jarak yang sangat jauh [1].

Metode saving matriks adalah metode yang digunakan untuk menentukan rute terbaik dengan mempertimbangkan jarak yang dilalui, jumlah kendaraan yang akan digunakan dan jumlah produk yang dapat dimuat kendaraan dalam pengiriman produk ke konsumen agar proses distribusi optimal [7]. Menurut Pujawan, saving matriks pada hakekatnya adalah metode untuk meminimumkan jarak atau waktu atau ongkos dengan mempertimbangkan kendalakendala yang ada [2]. Langkah-langkah yang harus dikerjakan adalah sebagai berikut: mengidentifikasikan matriks jarak, mengidentifikasikan matriks penghematan (saving matriks), mengalokasikan toko ke kendaraan atau rute, dan mengurutkan toko (tujuan) dalam rute yang sudah teridentifikasi.

Berikut ini merupakan rumus-rumus yang digunakan untuk melakukan perhitungan saving matriks

$$
\begin{aligned}
& J(x, y)=\sqrt{\left(x_{1}-x_{2}\right)+\left(y_{1}-y_{2}\right)} \\
& S(x, y)=J(G, x)+J(G . y)-J(x, y)
\end{aligned}
$$

\section{METODOLOGI PENELITIAN}

Metodologi penelitian pada penelitian dapat dilihat pada Gambar 1. 


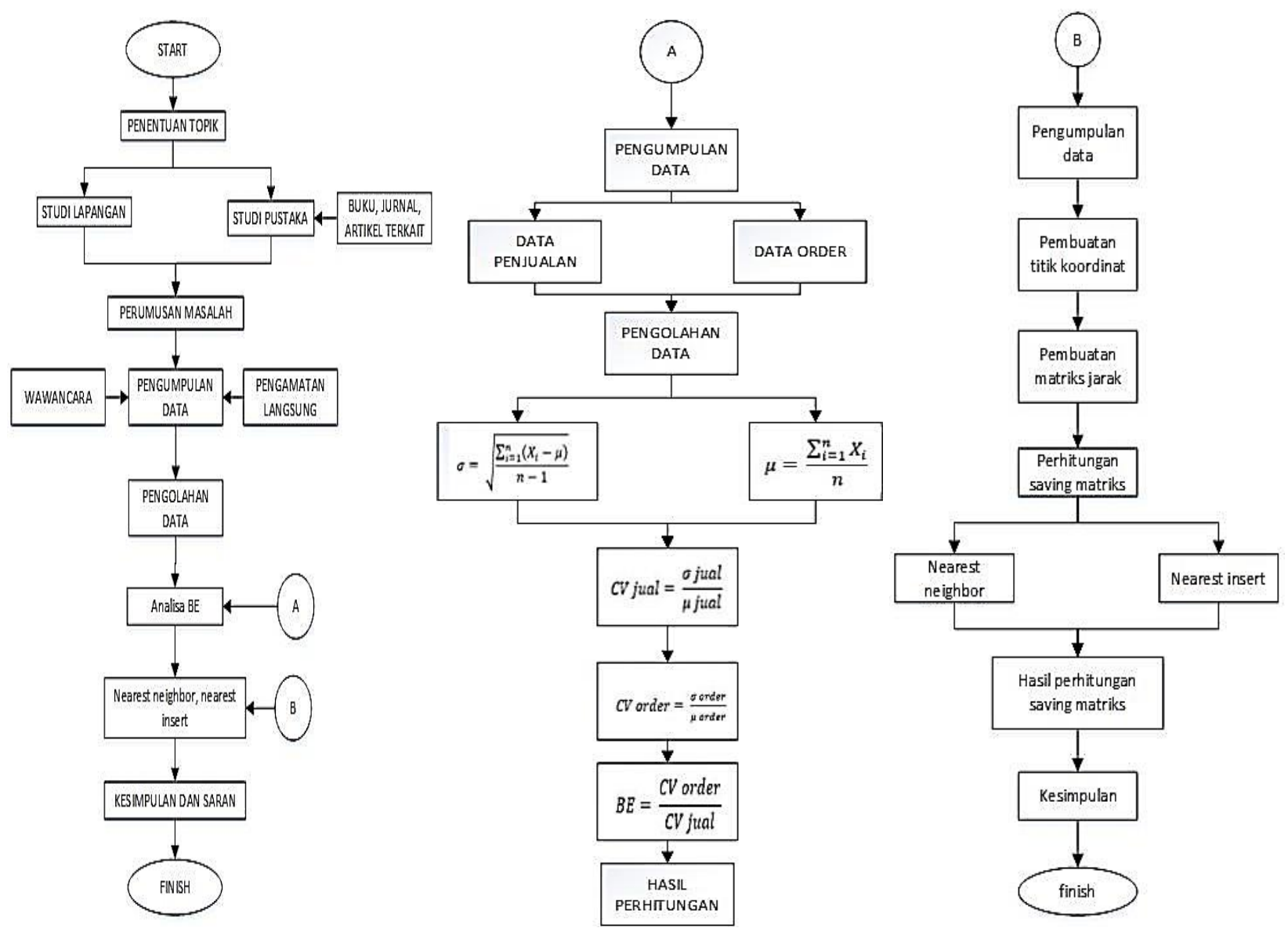

Gambar 1. Flowchart Metodologi Penelitian

\section{HASIL DAN PEMBAHASAN}

Berdasarkan data yang telah diperoleh dari perusahaan maka didapatkan hasil berupa data-data konsumen termasuk didalamnya adalah kota tempat konsumen berada dan produk apa saja yang dikirimkan ke kota tersebut, kota tempat konsumen tersebut adalah sebagai berikut Jakarta, Samarinda, Banjarmasin, Semarang, Surakarta, Yogyakarta, Makasar, Bekasi, Bandung, Palembang, Medan, Surabaya, Malang, Balikpapan. Penelitian ini meneliti tentang tingkat bullwhip effect yang terjadi pada setiap produk dan ritel, dimana produk yang diamati adalah produk BL75C, HK910A dan HK910B. konsumen yang akan diamati adalah konsumen dari kota Banjarmasin, Semarang, Surakarta, Makasar, Bekasi, Bandung, Medan, karena ketuju kota tersebut mempunyai tingkat pemesanan terhadap ketiga produk tersebut secara berkala, selama satu bulan. Berdasarkan hasil penelitian yang telah dilakukan maka didapatkan hasil berupa tingkat bullwhip effect yang terjadi pada perusahaan, dengan menggunakan rumus sebagai berikut.

Contoh perhitungan BE:

Berikut contoh perhitungan BE untuk ritel Banjarmasin untuk produk BL75C:

$$
\begin{aligned}
\mu \text { order } & =\frac{(96+130+100+0)}{4}=\frac{326}{4}=81,5 \\
\sigma \text { order } & =\sqrt{\frac{(96-81,5)^{2}+(130-81,5)^{2}+(100-81,5)^{2}+(0-81,5)^{2}}{4-1}} \\
& =\sqrt{\frac{210,25+2351,25+342,25+6642,25}{3}}=\sqrt{\frac{9547}{3}} \\
& =\sqrt{3182,33} \\
& =56.412
\end{aligned}
$$

CV order $=\frac{\sigma \text { order }}{\mu \text { order }}=\frac{56,412}{81,5}=0,692$ 
Usulan Perbaikan Rute Pendistribusian produk dengan Menggunakan Analisis Bullwhip Effect,

Metode Nearest Insert dan Nearest Neighbor (Studi Kasus di PT. YNP)

Iphov Kumala Sriwana, Ahmad dan Audi Frisbert Rewa

$$
\begin{aligned}
& \begin{aligned}
& \mu \text { jual }=\frac{(40+100+80+0)}{4}=\frac{220}{4}=55 \\
& \begin{aligned}
\sigma \text { jual } & =\sqrt{\frac{(40-55)^{2}+(100-55)^{2}+(80-55)^{2}+(0-55)^{2}}{4-1}} \\
& =\sqrt{\frac{225+2025+625+3025}{3}}=\sqrt{\frac{5900}{3}}=\sqrt{1966,66}=44,347
\end{aligned} \\
& \text { CV jual }=\frac{\sigma \text { jual }}{\mu \text { jual }}=\frac{44.347}{55}=0,806
\end{aligned} \\
& \mathrm{BE}=\frac{\mathrm{CV} \text { order }}{\mathrm{CV} \text { jual }}=\frac{0,692}{0,806}=0,85 \approx 0,9
\end{aligned}
$$

Tabel 1. Tingkat Bullwhip effect pada Setiap Produk

\begin{tabular}{ccccc}
\hline Produk & AVR & STD & CV & BE \\
\hline \multirow{2}{*}{ BL75C } & 416,5 & 155,6 & 0,4 & \multirow{2}{*}{0,9} \\
\cline { 2 - 4 } & 618,5 & 192,0 & 0,3 & \\
\hline \multirow{2}{*}{ HK910A } & 867,0 & 293,6 & 0,3 & \multirow{2}{*}{0,8} \\
\cline { 2 - 4 } & 1159,8 & 328,3 & 0,3 & \\
\hline \multirow{2}{*}{ HK910B } & 718,0 & 401,3 & 0,6 & \multirow{2}{*}{0,9} \\
\cline { 2 - 4 } & 976,0 & 501,4 & 0,5 & 0 \\
\hline
\end{tabular}

Berdasar hasil analisis bullwhip effect yang terjadi diperusahaan maka dapat dilihat bahwa terdapat 3 buah produk yaitu BL75C, HK910A, HK910B mengalami bullwhip effect yang mempunyai nilai sebesar 0,9 untuk produk BL75C, 0,8 untuk produk HK910A, dan 0,9 untuk produk HK910B, yang artinya adanya variabilitas atau ketidaksamaan antara permintaan dan penjualan untuk produk HK910A dan BL75C.

Selanjutnya dilakukan perhitungan bullwhip effect untuk setiap konsumen (kota), berdasarkan penelitian maka didapatkan hasil seperti ditunjukkan Tabel 2.

Berdasarkan Tabel 2 dapat dilihat bahwa kota Jakarta mempunyai nilai BE sebesar 0,811 yang menandakan tingkat variabilitas permintaan dan penjualan yang terjadi pada ritel ini tidak terlalu tinggi, sedangkan pada ritel Bandung, Semarang, dan Surakarta mempunyai nilai BE sebesar 0,99, 0,96, 0,96 yang menunjukan bahwa tingkat variabilitas permintaan dan penjualan yang terjadi pada ketiga ritel ini cukup tinggi. sehingga perlunya pengawasan lebih lanjut pada ketiga ritel tersebut.

Setelah mendapatkan hasil analisis BE disetiap ritel dilanjutkan dengan mencari jarak pengiriman yang lebih optimal untuk perusahaan, dilakukan dengan menggunakan rumus perhitungan saving matriks, dimana hasil saving matriks nanti akan dibandingkan dengan rute pengiriman awal yang dimiliki perusahaan. Dibawah ini dapat dilihat Rute pendistribusian awal yang dilakukan oleh pihak perusahaan

Tabel 2. Tabel BE untuk Setiap Ritel

\begin{tabular}{crrrr}
\hline \multicolumn{5}{c}{ Nilai BE untuk setiap ritel } \\
\hline Produk & AVR & \multicolumn{1}{c}{ STD } & CV & BE \\
\hline Jakarta & 172 & 168,6653 & 0,980612 & \multirow{2}{*}{0,811349} \\
& 252,5 & 200,8938 & 0,795619 & \\
\hline Banjarmasin & 208,5 & 153,0261 & 0,733938 & \multirow{2}{*}{0,888428} \\
& 289 & 188,4427 & 0,652051 & \\
\hline Semarang & 90,5 & 56,45942 & 0,602368 & \multirow{2}{*}{0,965869} \\
& 133 & 80,14154 & 0,602568 & \\
\hline Surakarta & 310,25 & 233,937 & 0,75403 & \multirow{2}{*}{0,966077} \\
& 458,25 & 333,8127 & 0,728451 & \\
\hline Makassar & 328,25 & 471,5141 & 1,436448 & \multirow{2}{*}{0,877873} \\
& 464 & 585,1131 & 1,26102 & \\
\hline Bekasi & 271 & 356,073 & 1,313923 & \multirow{2}{*}{0,856186} \\
& 375 & 421,861 & 1,124963 & \\
\hline Bandung & 183 & 211,7136 & 1,156905 & \multirow{2}{*}{0,998182} \\
& 267,5 & 308,9094 & 1,154801 & \\
\hline Medan & 129,5 & 109,8772 & 0,848473 & \multirow{2}{*}{0,864291} \\
& 171,5 & 125,7657 & 0,733327 & \\
\hline
\end{tabular}

Perhitungan saving matrik dilakukan dengan melakukan beberapa langkah yaitu, menentukan titik koordinat, menentukan matriks jarak, mengidentifikasikan saving matriks dan mengurutkan konsumen.

Setelah mencari titik koordinat di peta, diubah ke dalam bentuk tabel seperti yang

Tabel 3. Empat Rute Pendistribusian Awal

\begin{tabular}{cllrl}
\hline Pusat Produksi & Rute & Urutan & Jarak Tempuh & Biaya Pengiriman \\
\hline \multirow{5}{*}{ PT. YNP } & Rute 1 & JKT-BKS-BDG-JKT & 342 & Rp 3.000.000 \\
& Rute 2 & JKT-SMG-SRKT-JKT & 1561 & Rp 7.000.000 \\
& Rute 3 & JKT-MDN-JKT & 3874 & Rp 8.000.000 \\
& Rute 4 & JKT-BNJR-JKT & 3192 & Rp 8.000.000 \\
& Rute 5 & JKT-MKS-JKT & 3158 & Rp 8.000.000 \\
\hline
\end{tabular}


terlihat pada tabel di bawah ini.

\section{Tabel 4. Titik Koordinat Konsumen}

\begin{tabular}{cccc}
\hline Kode & Konsumen & $\begin{array}{c}\text { Koordinat } \\
\text { Konsumen }\end{array}$ & $\begin{array}{c}\text { Koordinat } \\
\text { X }\end{array}$ \\
\hline JKT & JAKARTA & 0 & 0 \\
BKS & Bekasi & 3 & 0 \\
BDG & Bandung & 19 & 7 \\
SRKT & Surakarta & 47 & -14 \\
SMG & Semarang & 42 & 0 \\
MDN & Medan & -95 & 105 \\
BNJR & Banjarmasin & 92 & 30 \\
MKS & Makassar & 149 & 11 \\
\hline
\end{tabular}

Tabel 4 di atas menunjukan titik koordinat dari konsumen perusahaan, contoh perhitungan matriks jarak:

$$
\mathrm{J}(\text { Jakarta, Banjarmasin })=\sqrt{(0-92)^{2}+(0-30)^{2}}
$$

Setelah didapatkan titik koordinat, dilanjutkan dengan membuat matriks jarak berdasarkan titik koordinat seperti yang terlihat pada Tabel 4.

Tabel 5 merupakan hasil perhitungan Matriks jarak dengan menggunakan rumus perhitungan sebagai berikut:

Contoh perhitungan Saving matriks:

S (Jakarta, Banjarmasin $)=96,8+42,0-58,3=80,5$

Hasil perhitungan saving matriks dapat dilihat pada Tabel 6 . Tabel 6 menunjukan pengelompokkan konsumen berdasarkan rute yang ditetapkan setelah melakukan perhitungan saving matriks.

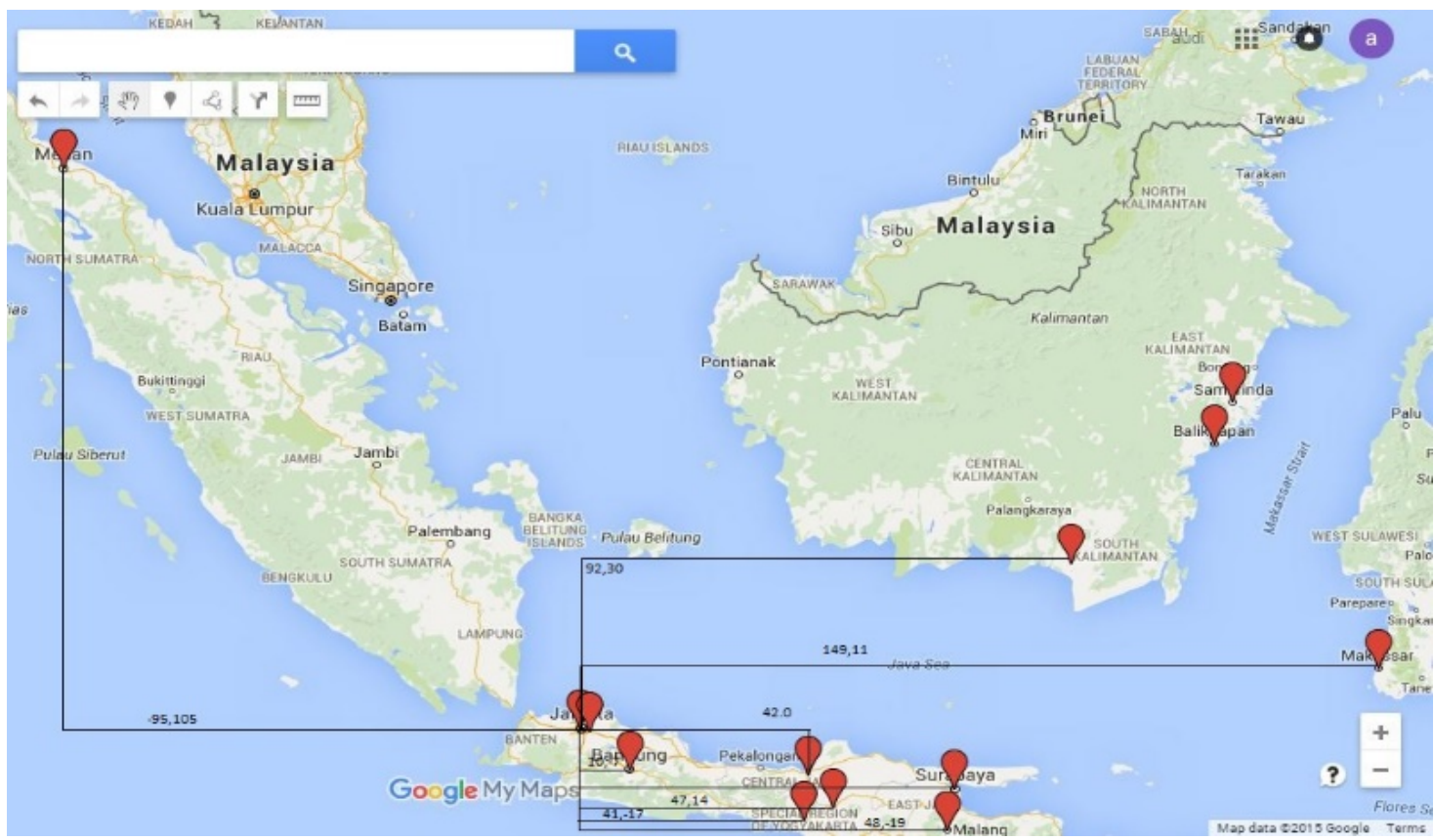

Gambar 2. Koordinat Konsumen

Tabel 5. Tabel Matriks Jarak

\begin{tabular}{lrrrrrrrr}
\hline & JKT & BNJR & SMRG & SRKT & MKS & BKS & BDG & MDN \\
\hline BJNR & 96,8 & 0,0 & & & & & & \\
SMG & 41,0 & 58,3 & 0,0 & & & & & \\
SKRT & 49,0 & 62,9 & 14,9 & 0,0 & & & & \\
MKS & 149,4 & 60,1 & 107,6 & 105,0 & 0,0 & & & \\
BKS & 3,0 & 93,9 & 39,0 & 46,2 & 146,4 & 0,0 & & \\
BDG & 12,2 & 85,2 & 32,8 & 42,5 & 139,1 & 9,9 & 0,0 & \\
MDN & 141,6 & 201,5 & 172,6 & 185,3 & 261,5 & 143,6 & 143,6 & 0,0 \\
\hline
\end{tabular}


Usulan Perbaikan Rute Pendistribusian produk dengan Menggunakan Analisis Bullwhip Effect, Metode Nearest Insert dan Nearest Neighbor (Studi Kasus di PT. YNP)

Iphov Kumala Sriwana, Ahmad dan Audi Frisbert Rewa

Tabel 6. Tabel Saving Matriks

\begin{tabular}{|c|c|c|c|c|c|c|c|c|}
\hline \multicolumn{9}{|c|}{ Matriks Penghematan } \\
\hline & & BNJR & SMG & SRKT & MKS & BKS & BDG & MDN \\
\hline BNJR & RUTE 1 & 00 & & & & & & \\
\hline SMG & RUTE 2 & 80,5 & 0,0 & & & & & \\
\hline SRKT & RUTE 3 & 82,9 & 76,2 & 0,0 & & & & \\
\hline MKS & RUTE 4 & 186,1 & 83,8 & 93,4 & 0,0 & & & \\
\hline BKS & RUTE 5 & 5,8 & 6,0 & 5,9 & 6,0 & 0,0 & & \\
\hline BDG & RUTE 6 & 23,8 & 21,4 & 18,7 & 22,6 & 5,3 & 0,0 & \\
\hline MDN & RUTE 7 & 36,9 & 11,4 & 5,4 & 29,5 & 1,0 & 10,2 & 0,0 \\
\hline & ER & 1126 & 432 & 1833 & 1216 & 1010 & 540 & 290 \\
\hline
\end{tabular}

Tabel 7. Hasil Saving Matriks.

\begin{tabular}{cccc}
\hline Metode & Rute & Urutan & Jarak Tempuh \\
\hline \multirow{5}{*}{ Awal } & Rute 1 & JKT-BKS-BDG-JKT & 342 \\
& Rute 2 & JKT-SMG-SRKT-JKT & 1561 \\
& Rute 3 & JKT-MDN-JKT & 3874 \\
& Rute 4 & JKT-BNJR-JKT & 3192 \\
& Rute 5 & JKT-MKS-JKT & 3158 \\
\hline \multirow{3}{*}{ Nearest Insert } & Rute 1 & JKT-BNJR-MKS-JKT & 4745 \\
& Rute 2 & JKT-SMF-SRKT-JKT & 1561 \\
& Rute 3 & JKT-BKS-BDG-MDN-JKT & 4066 \\
\hline \multirow{3}{*}{ Nearest Neighbor } & Rute 1 & JKT-BNJR-MKS-JKT & 4745 \\
& Rute 2 & JKT-SMG-SRKT-JKT & 1561 \\
& Rute 3 & JKT-BKSOMDN-JKT & 4066 \\
\hline
\end{tabular}

Tabel 6 menunjukan hasil rute perbaikan yang didapatkan dengan menggunakan metode nearest insert dan nearest neighbor.

\section{KESIMPULAN}

Berdasarkan penelitian yang telah dilakukan maka diperoleh beberapa kesimpulan yaitu: Penyebab terjadinya fenomena bullwhip effect pada perusahaan adalah karena adanya ketidaksesuaian dalam penyampaian informasi yang diberikan oleh pihak ritel yang menyebabkan terjadinya variasi permintaan yang menyebabkan timbul fenomena bullwhip effect. Berdasarkan penelitian yang dilakukan maka didapatkan hasil sebagai berikut, pada kota Banjarmasin sebesar 1,0 untuk produk HK910A, dan HK910B, Semarang sebesar 1,0 untuk produk BL75C dan HK910A, Surakarta sebesar 1,0 untuk produk HK910A, Makassar sebesar 0,9 untuk produk BL75C, HK910A dan HK910B, Bekasi sebesar 1,1 untuk produk BL75C, Bandung sebesar 1,0 untuk produk BL75C, HK910A dan HK910B, dan Medan sebesar 1,2 untuk produk Bl75C. Bullwhip effect dapat dicegah atau di kurangi dengan menggunakan beberapa cara, seperti melakukan perhitungan peramalan yang lebih akurat agar tidak terjadi variasi permintaan atau bias menggunakan sebuah program untuk mengatur jumlah produksi yang harus diproduksi periode berikutnya. Berdasarkan hasil penelitian maka didapatkan jalur pendistribusian yang lebih optimal dibandingkan dengan jalur pendistribusian awal yaitu Rute 1 Jakarta Banjarmasin - Makassar - Jakarta, Rute 2 Jakarta - Semarang - Surakarta - Jakarta, dan Rute 3 Jakarta - Bekasi - Bandung - Medan Jakarta. Berdasarkan hasil penelitian maka didapatkan bahwa rute usulan yang diberikan oleh peneliti mempunyai tingkat penghematan jarak tempuh sebesar $14 \%$ atau terjadinya penghematan pada biaya pengiriman sebesar Rp. 7.000.000

\section{DAFTAR PUSTAKA}

[1]. Pujawan, I Nyoman. (2005). "Supply Chain Management". $1^{\text {st }}$ Edition. Surabaya: PT. Guna Widya.

[2]. Chopra, Sunil \& Meindl, Peter. (2007). "Supply Chain Management: Strategy, 
Planning \& Operations”. $3^{\text {rd }}$ Edition. London: Pearson Education Ltd.

[3]. Herjanto, Eddy. (2008). "Manajemen Produksi dan Operasi”. Edisi Ke-2. Jakarta: PT. Gramedia Widiasarana Indonesia.

[4]. Nur Hayati, Enty. (2014). "Supply Chain Management (SCM) dan Logistic Management”. Jurnal Dinamika Teknik, Vol. 8 No. 1. Semarang: Universitas Stikubank.

[5]. Bowersox, Donald John. (2002). “Manajemen Logistik Terpadu”. Jakarta: Bumi Aksara.
[6]. Levy, Michael \& Weitz, BA. (2002). "Retail Management". 6 ${ }^{\text {th }}$ Edition. New York: McGraw Hill.

[7]. Sarjono, Haryadi \& Wijaya, Jeffry. (2015). "Optimization of The Determination of The Route With The Approach of Farthest Insert Method". Medwell Journal, The Social Sciences 10, Page: 318-324. Jakarta: Universitas Bina Nusantara. 